\title{
PENGENDAPAN URANIUM DAN THORIUM HASIL PELARUTAN SLAG II
}

\section{URANIUM AND THORIUM PRECIPITATION FROM SOLUTION OF SLAG II}

\author{
Mutia Anggraini*, Budi Sarono, Sugeng Waluyo, Rusydi, dan Sujono \\ Pusat Teknologi Bahan Galian Nuklir - BATAN, Jalan Lebak Bulus Raya 9, Pasar Jumat, Jakarta Selatan \\ *E-mail: mutiaa@batan.go.id
}

Naskah diterima: 1 Oktober 2015, direvisi: 19 Oktober 2015, disetujui: 22 Oktober 2015

\begin{abstract}
ABSTRAK
Proses peleburan timah menghasilkan limbah berupa slag II dalam jumlah besar. Slag II sebagai terak pada proses peleburan timah masih mengandung beberapa unsur utama antara lain 0,0619\% uranium, 0,530\% thorium, 0,179\% $\mathrm{P}_{2} \mathrm{O}_{5}$, dan 6,194\% logam tanah jarang (LTJ) oksida total. Berdasarkan fakta tersebut, maka sangat menarik untuk meneliti pengolahan slag II, terutama untuk memisahkan uranium dan thorium yang terkandung di dalamnya. Uranium dan thorium dilarutkan dengan pelarut asam $\left(\mathrm{H}_{2} \mathrm{SO}_{4}\right)$. Recovery pelarutan slag II dari hasil peleburan timah pada kondisi optimum adalah 98,52\% uranium, 83,16\% thorium, 97,22\% fosfat, dan 69,62\% LTJ. Uranium, thorium, LTJ, dan fosfat yang telah terlarut diendapkan agar masing-masing unsur terpisah. Faktor yang mempengaruhi kesempurnaan reaksi pada pengendapan antara lain reagen yang digunakan, $\mathrm{pH}$ reaksi, suhu, dan waktu. $\mathrm{NH}_{4} \mathrm{OH}$ digunakan sebagai reagen pengendapan dengan kondisi optimum proses pada $\mathrm{pH} 4$. Suhu dan waktu reaksi tidak mempengaruhi proses. Recovery pengendapan yang dihasilkan adalah $93,84 \%$ uranium dan $84,33 \%$ thorium.
\end{abstract}

Kata kunci: pengendapan, uranium, thorium, slag II, recovery

\section{ABSTRACT}

Tin smelting process produces waste in the form of large amount of slag II. Slag II still consist of major elements such as $0.0619 \%$ uranium, $0.530 \%$ thorium, $0.179 \% \mathrm{P}_{2} \mathrm{O}_{5}$ and 6.194\% RE total oxide. Based on that fact, the processing of slag II is interesting to be researched, particularly in separating uranium and thorium which contained in slag II. Uranium and thorium dissolved using acid reagent $\left(\mathrm{H}_{2} \mathrm{SO}_{4}\right)$. Percentage recovery of uranium, thorium, phosphate and RE oxides by dissolution method are 98.52\%, 83.16\%, 97.22\%, and $69.62 \%$ respectively. Dissolved uranium, thorium, phosphat, and RE were each precipitated. The factors which considerable affect the precipitation process are reagent, $\mathrm{pH}$, temperature, and time. $\mathrm{NH}_{4} \mathrm{OH}$ is used as precipitation reagent, optimum condition are $\mathrm{pH}$ 4. Temperature and time reaction did not influence this reaction. Percentage recovery of this precipitation process at optimum condition are $93.84 \%$ uranium and $84.33 \%$ thorium.

Keywords: precipitation, uranium, thorium, slag II, recovery 


\section{PENDAHULUAN}

Proses peleburan timah menghasilkan limbah berupa slag II dalam jumlah besar. Slag II adalah limbah pengolahan timah yang mengeras menyerupai batu dan mengandung $\mathrm{Sn}, \mathrm{Si}$, serta unsur radioaktif berupa uranium dan thorium ${ }^{[1]}$. Tingkat kepadatan slag II diperoleh 3,076 kg/ $\mathrm{cm}^{3}$. Dengan kepadatan sebesar itu, tin slag dapat dimanfaatkan sebagai bahan pengganti agregat/split/batu pecah yang biasa digunakan pada bahan campuran aspal maupun beton ${ }^{[2]}$.

Pemanfaatan slag II sebagai bahan pengganti agregat/split/batu pecah tidak diperbolehkan karena slag II mengandung unsur radioaktif. Hasil analisis slag II dengan metode XRF di Puslitbang Tekmira Bandung menunjukkan kadar kandungan $\mathrm{U}_{3} \mathrm{O}_{8}$ sebesar $0,0619 \%, \mathrm{ThO}_{2} 0,53 \%, \mathrm{P}_{2} \mathrm{O}_{5} 0,179 \%$, dan LTJ oksida total $6,194 \%^{[3]}$. Kadar unsur radioaktif pada slag II masih sangat tinggi. Oleh karena itu, perlu dilakukan pemisahan unsur radioaktif dari slag II tersebut.

Proses pelarutan uranium, thorium, dan LTJ pada slag II telah dilakukan dan didapat kondisi optimum proses, yaitu jumlah $\mathrm{H}_{2} \mathrm{SO}_{4}$ yang ditambahkan sebagai reagen pelarutan adalah 1 kali berat umpan dengan waktu dan suhu pelarutan optimal adalah 60 menit dan $43^{\circ} \mathrm{C}$. Recovery pelarutan slag II dari hasil peleburan timah pada kondisi optimum adalah $98,53 \%$ uranium, $83,16 \%$ thorium, $97,22 \%$ fosfat, dan $69,62 \% \mathrm{LTJ}^{[4]}$. Unsurunsur radioaktif yang telah larut kemudian diendapkan menggunakan reagen pengendapan. Tujuan penelitian ini adalah mencari kondisi optimum pemisahan uranium dan thorium dengan metode pengendapan.

Faktor yang mempengaruhi kesempurnaan reaksi pada pengendapan uranium dan thorium antara lain reagen yang digunakan, konsumsi reagen yang ditambahkan pada proses pengendapan, suhu, dan waktu pengendapan. Reagen basa digunakan dalam proses pengendapan. Hal ini karena Ksp (hasil kali kelarutan) unsur uranium dan thorium rendah jika direaksikan dengan reagen basa ${ }^{[5]}$. Semakin rendah nilai Ksp maka unsur tersebut mudah mengendap. Reagen basa yang digunakan pada penelitian ini adalah $\mathrm{NaOH}$ dan $\mathrm{NH}_{4} \mathrm{OH}$. Konsumsi reagen yang digunakan akan berpengaruh pada optimasi proses sehingga proses pemisahan uranium dan thorium menjadi maksimal.

Faktor lain yang berpengaruh pada proses pengendapan adalah waktu reaksi dan kecepatan reaksi. Persamaan kecepatan reaksi dapat ditulis sebagai berikut ${ }^{[6]}$ :

$$
\mathrm{r}=\frac{d c}{d t}=\mathrm{k} \cdot C^{\mathrm{n}}
$$

$\frac{d e}{d t}=r=$ Kecepatan reaksi, $\mathrm{k}=$ Konstanta kecepatan reaksi, $\mathrm{C}=$ Konsentrasi, $\mathrm{n}=$ orde reaksi

Waktu pengendapan adalah waktu yang diperlukan agar reaksi pengendapan dan uranium dan thorium dapat berlangsung sempurna. Kecepatan reaksi akan mempengaruhi waktu reaksi. Semakin besar kecepatan reaksi maka akan semakin cepat waktu reaksi.

Reaksi yang terjadi pada proses pengendapan uranium dan throrium sulfat hasil pelarutan slag II adalah sebagai berikut: 


\author{
Dengan $\mathrm{NaOH}^{[7]}$ : \\ $\mathrm{RE}_{2}\left(\mathrm{SO}_{4}\right)_{3}+6 \mathrm{NaOH} \rightarrow 2 \mathrm{RE}(\mathrm{OH})_{3}+3 \mathrm{Na}_{2} \mathrm{SO}_{4}$ \\ $\mathrm{Th}\left(\mathrm{SO}_{4}\right)_{2}+4 \mathrm{NaOH} \rightarrow \mathrm{Th}(\mathrm{OH})_{4}+2 \mathrm{Na}_{2} \mathrm{SO}_{4}$ \\ $\mathrm{UO}_{2}\left(\mathrm{SO}_{4}\right)+2 \mathrm{NaOH} \rightarrow \mathrm{UO}_{2}(\mathrm{OH})_{2}+\mathrm{Na}_{2} \mathrm{SO}_{4}$ \\ Dengan $\mathrm{NH}_{4} \mathrm{OH}^{[8]}$ : \\ $\mathrm{RE}_{2}\left(\mathrm{SO}_{4}\right)_{3}+6 \mathrm{NH}_{4} \mathrm{OH} \rightarrow 2 \mathrm{RE}(\mathrm{OH})_{3}+3\left(\mathrm{NH}_{4}\right)_{2} \mathrm{SO}_{4}$ \\ $\mathrm{Th}\left(\mathrm{SO}_{4}\right)_{2}+4 \mathrm{NH}_{4} \mathrm{OH} \rightarrow \mathrm{Th}(\mathrm{OH})_{4}+2\left(\mathrm{NH}_{4}\right)_{2} \mathrm{SO}_{4}$ \\ $\mathrm{UO}_{2}\left(\mathrm{SO}_{4}\right)_{2}+2 \mathrm{NH}_{4} \mathrm{OH} \rightarrow \mathrm{UO}_{2}(\mathrm{OH})_{2}+2\left(\mathrm{NH}_{4}\right)_{2} \mathrm{SO}_{4}$
}

\section{METODOLOGI}

Bongkahan slag II dengan ukuran bijih lebih dari 20 mesh digiling dengan crusher kemudian dihaluskan dengan disk mill dan diayak sehingga diperoleh slag II ukuran bijih $-20+48$ mesh. Slag II berukuran $-20+48$ mesh dilebur dengan $\mathrm{NaOH}$ dengan perbandingan $1: 2$ pada suhu $700^{\circ} \mathrm{C}$ selama 2 jam. Hasil peleburan kemudian dihaluskan menggunakan mortal dan diayak sehingga diperoleh slag II berukuran lolos 325 mesh (-325 mesh). Slag II hasil peleburan dilarutkan dengan $\mathrm{H}_{2} \mathrm{SO}_{4}$ pada perbandingan $1: 1$, selama 60 menit pada suhu $43^{\circ} \mathrm{C}$ dan dihasilkan larutan yang mengandung uranium dan thorium. Larutan ini digunakan sebagai umpan pengendapan.

Pengendapan bertujuan untuk memisahkan uranium dan thorium pada larutan sulfat. Proses pengendapan dilakukan dengan memvariasikan beberapa kondisi proses antara lain: variasi reagen $(\mathrm{NaOH}$ dan $\mathrm{NH}_{4} \mathrm{OH}$ ), variasi konsumsi reagen (variasi pH) pada $\mathrm{pH} 4 ; 4,5 ; 5 ; 5,5 ; 6 ; 6,5 ; 7$, variasi suhu pelarutan, pada suhu $30,40,45,50,55$, 60,70 , dan $80^{\circ} \mathrm{C}$, dan variasi waktu pelarutan selama 10, 15, 30, 45, 60, 75, 90, dan 120 menit. Endapan dan filtrat yang dihasilkan dianalisis dengan ICP-OES.

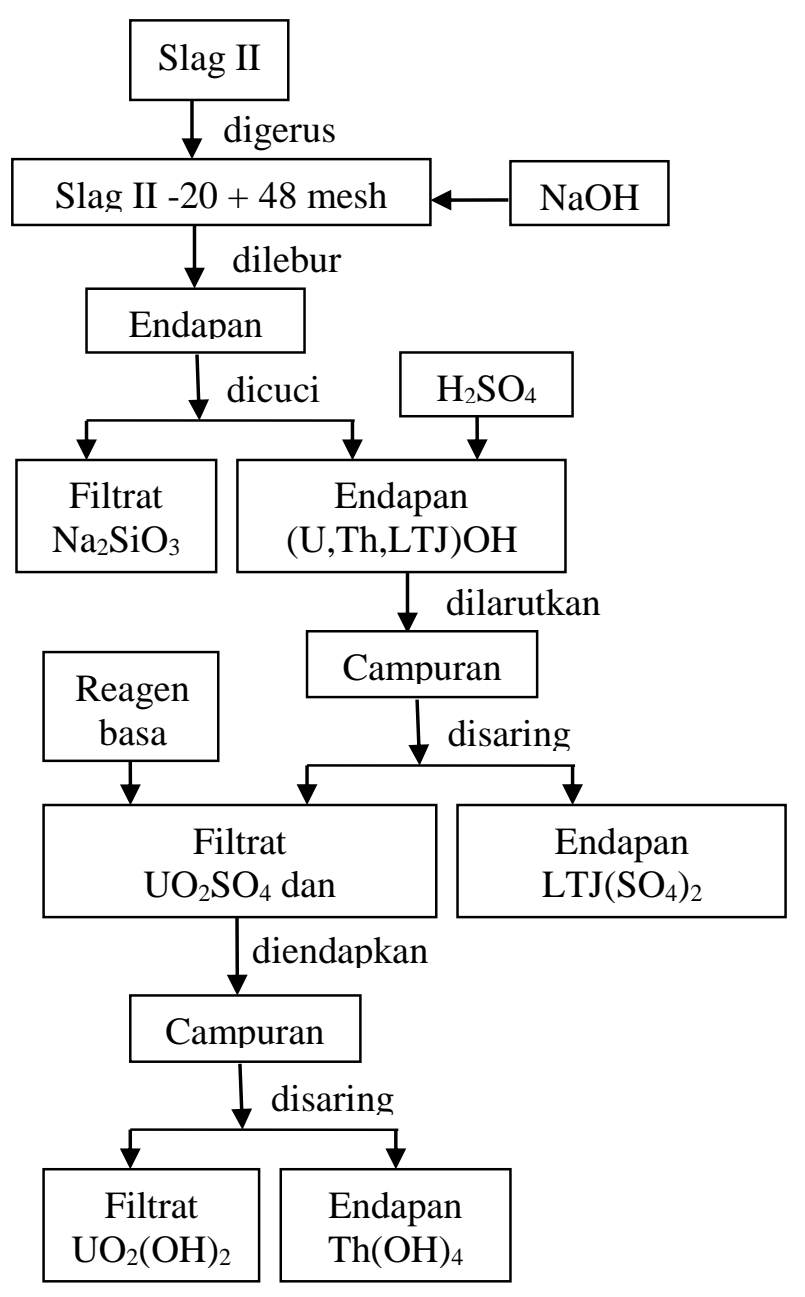

Gambar 1. Diagram alir proses pemisahan uranium dan thorium slag II peleburan timah.

Penentuan kondisi optimal proses pemisahan uranium dan thorium dengan metode pengendapan larutan hasil pelarutan slag II dilihat berdasarkan kesempurnaan reaksi pengendapan. Kesempurnaan reaksi pengendapan uranium dan thorium dapat ditentukan berdasarkan recovery pengendapan. Recovery dapat dicari dengan persamaan 2, sebagai berikut ${ }^{[9]}$.

$\%$ Recovery $=\frac{\mathrm{w}_{\mathrm{u}}-\mathrm{w}_{\mathrm{r}}}{\mathrm{w}_{\mathrm{u}}} \times 100 \%$

$\%$ Recovery $=$ recovery unsur $(\%), \mathrm{W}_{\mathrm{U}}=$ berat unsur dalam umpan $(\mathrm{g}), \mathrm{W}_{\mathrm{R}}=$ berat unsur dalam endapan (g). 
Penentuan berat uranium, thorium, LTJ dan fosfat hasil pengendapan dapat dihitung dengan persamaan $3^{[9]}$.

$$
\mathrm{W}=\frac{\mathrm{C}_{\mathrm{u}} x V_{f}}{10^{6}}
$$

$\mathrm{W}=$ berat unsur $(\mathrm{g}), \mathrm{C}_{\mathrm{u}}=$ kadar unsur $(\mathrm{mg} / \mathrm{L})$, $\mathrm{V}_{\mathrm{f}}=$ volume filtrat $(\mathrm{mL})$.

\section{HASIL DAN PEMBAHASAN}

Uranium dan thorium dalam slag II yang telah melalui proses peleburan dengan $\mathrm{NaOH}$ dan pelarutan dengan $\mathrm{H}_{2} \mathrm{SO}_{4}$ akan berubah menjadi larutan uranium dan thorium sulfat. Larutan sulfat yang mengandung uranium dan thorium telah bebas dari LTJ, fosfat, dan silika yang menutupi permukaan slag II. Uranium dan thorium dalam larutan sulfat dapat dipisahkan dengan mereaksikan larutan tersebut dengan reagen basa, yaitu $\mathrm{NaOH}$ dan $\mathrm{NH}_{4} \mathrm{OH}$.

Proses pemisahan uranium dan thorium bergantung pada kondisi reaksi. Reaksi antara uranium dan thorium dengan $\mathrm{NaOH}$ dan $\mathrm{NH}_{4} \mathrm{OH}$ dapat mengendapkan uranium dan thorium secara bersamaan. Oleh sebab itu, perlu dicari kondisi optimum yang dapat memisahkan kedua unsur tersebut. Pada penelitian ini dilakukan variasi $\mathrm{pH}$. Pada $\mathrm{pH}$ tertentu, reaksi uranium dan thorium dengan reagen basa menghasilkan endapan thorium, sedangkan uranium tetap dalam larutan.

Larutan hasil reaksi uranium-thorium dengan $\mathrm{NaOH}$ dan $\mathrm{NH}_{4} \mathrm{OH}$ variasi $\mathrm{pH}$ dianalisis dengan ICP-OES pada limit deteksi $<10$ ppb. Kadar uranium dan thorium hasil analisis dengan ICP-OES terlihat pada Tabel 1.

Kadar uranium dalam larutan hampir sama dengan kadar thorium pada kondisi reaksi dengan $\mathrm{NaOH}$ pada $\mathrm{pH}$ 4. Sedangkan reaksi dengan $\mathrm{NH}_{4} \mathrm{OH}$ pada $\mathrm{pH}$ yang sama, kadar uranium lebih kecil dibandingkan kadar thorium. Kadar uranium dan thorium semakin berkurang dengan peningkatan $\mathrm{pH}$ reaksi. Peningkatan kondisi $\mathrm{pH}$ reaksi menyebabkan uranium dan thorium terendapkan secara bersamaan. Efektifitas proses pemisahan uranium dan thorium dapat dilihat dari persen recovery yang dihasilkan pada proses ini.

Recovery pemisahan uranium dan thorium variasi $\mathrm{pH}$ dengan reagen basa terlihat pada Gambar 3. Kondisi pengendapan pada suhu (T) $27^{\circ} \mathrm{C}$ dan waktu (t) 60 menit.

Tabel 1. Data hasil analisis unsur dalam larutan dengan ICP-OES (variasi $\mathrm{pH}$ ).

\begin{tabular}{ccccc}
\hline \multirow{2}{*}{$\mathbf{p H}$} & \multicolumn{4}{c}{ Kadar (ppm) } \\
\cline { 2 - 5 } & \multicolumn{2}{c}{$\mathbf{N a O H}$} & \multicolumn{2}{c}{$\mathbf{N H} \mathbf{O H}$} \\
\cline { 2 - 5 } $\mathbf{U}$ & $\mathbf{T h}$ & $\mathbf{U}$ & $\mathbf{T h}$ \\
\hline 4,00 & 50,62 & 54,00 & 19,41 & 57,80 \\
4,50 & 25,75 & 12,60 & 4,26 & 9,10 \\
5,07 & 10,45 & 9,10 & 2,04 & 6,40 \\
5,50 & 0,00 & 0,00 & 0,00 & 3,10 \\
6,02 & 0,00 & 0,00 & 0,00 & 3,00 \\
6,56 & 0,00 & 0,00 & 0,00 & 0,89 \\
7,09 & 0,00 & 0,00 & 0,00 & 0,00 \\
8,07 & 0,00 & 0,00 & 0,00 & 0,00 \\
\hline
\end{tabular}

Proses pengendapan dapat ditentukan dengan melihat nilai hasil kali kelarutan atau solubility product constant atau Ksp dari masing-masing senyawa. Nilai Ksp yang rendah mengindikasikan bahwa senyawa tersebut mudah diendapkan, sebaliknya jika Ksp suatu senyawa memiliki nilai yang tinggi maka senyawa tersebut susah diendapkan.

Pemisahan uranium dan thorium dengan metode pengendapan yang memanfaatkan perbedaan nilai Ksp kedua unsur dilakukan secara basa dengan reagen $\mathrm{NaOH}$ dan $\mathrm{NH}_{4} \mathrm{OH}$. Uranium dan thorium akan bereaksi dengan reagen basa membentuk uranium dan thorium hidroksida. Ksp uranium hidroksida $\left(\mathrm{UO}_{2}(\mathrm{OH})_{2}\right)$ sebesar $1,1 \times 10^{-22}$ dan thorium hidroksida $\left(\mathrm{Th}(\mathrm{OH})_{4}\right)$ sebesar $4 \times 10^{-45}{ }^{[10]}$. Nilai Ksp kedua unsur tersebut sangat kecil 
sehingga kedua unsur tersebut mudah terlebih dahulu sedangkan uranium tetap mengendap. Nilai Ksp thorium lebih kecil berada dalam filtrat sehingga uranium dan dibandingkan nilai Ksp uranium. Pada thorium dapat dipisahkan.

kondisi tertentu thorium akan mengendap
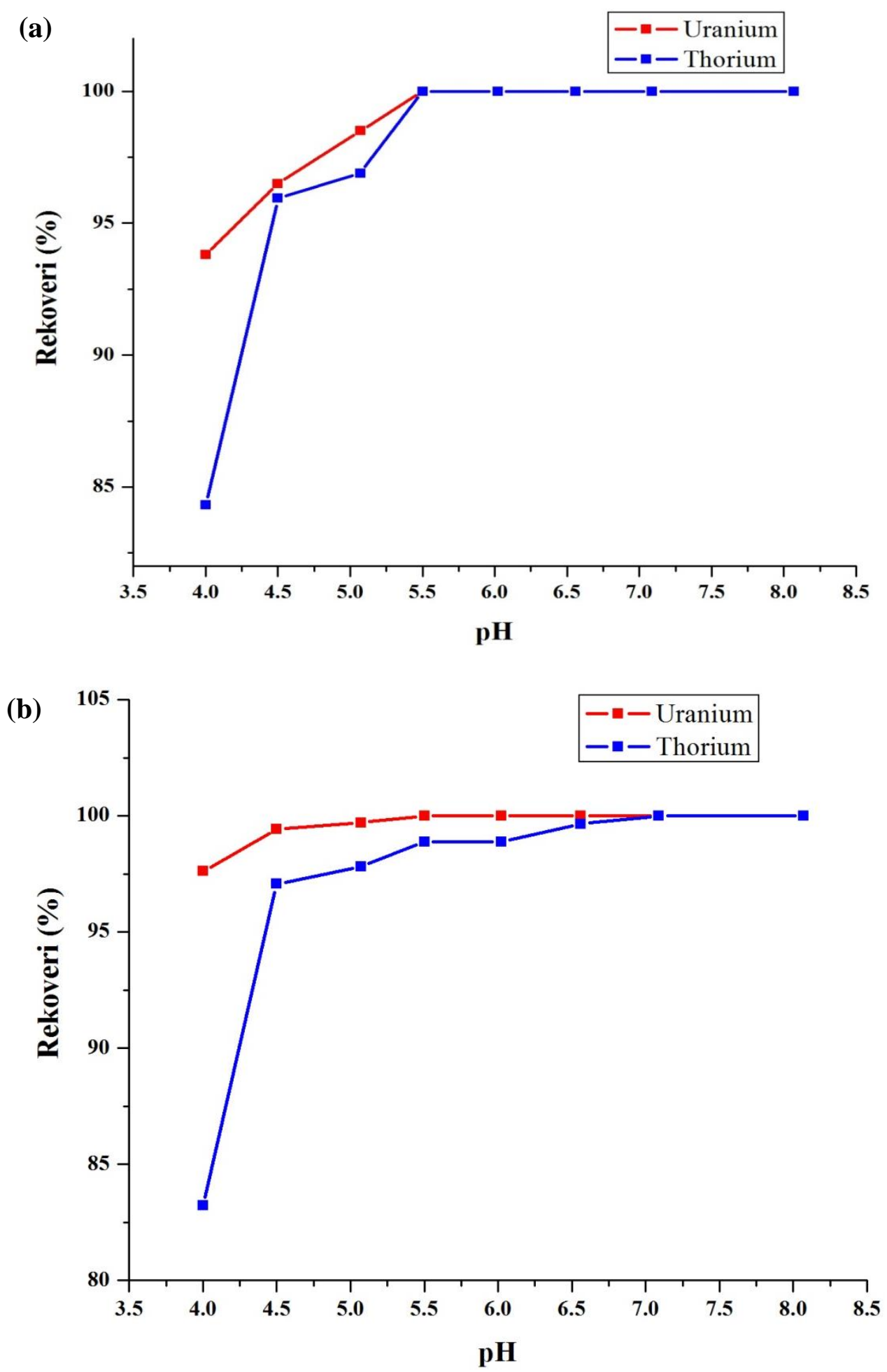

Gambar 3. Kurva recovery pengendapan variasi $\mathrm{pH}$ (a) reagen $\mathrm{NaOH}$ (b) reagen $\mathrm{NH}_{4} \mathrm{OH}$. 
Konsumsi $\mathrm{NaOH}$ dan $\mathrm{NH}_{4} \mathrm{OH}$ yang digunakan identik dengan $\mathrm{pH}$ larutan yang terukur setelah penambahan reagen. Recovery thorium dalam filtrat lebih rendah daripada recovery uranium pada $\mathrm{pH} 4$ seperti terlihat pada gambar 3. Recovery thorium $84,33 \%$ dan uranium $93,80 \%$ pada kondisi pengendapan dengan $\mathrm{NaOH}$ (Gambar 3a), sedangkan recovery thorium $83,23 \%$ dan uranium $97,62 \%$ dan pada kondisi pengendapan dengan $\mathrm{NH}_{4} \mathrm{OH}$ (Gambar 3b). Hal ini berarti thorium sudah mulai mengendap sedangkan uranium masih berada dalam filtrat. Penambahan nilai $\mathrm{pH}$ menyebabkan thorium terlarut dan berada bersama uranium dalam filtrat sehingga kedua unsur tersebut tidak dapat dipisahkan. Oleh sebab itu, $\mathrm{pH} 4$ digunakan sebagai $\mathrm{pH}$ optimum pemisahan uranium dan thorium dengan metode pengendapan basa.

Pengaruh $\mathrm{pH}$ terhadap hasil reaksi pengendapan uranium dan thorium dengan $\mathrm{NaOH}$ maupun $\mathrm{NH}_{4} \mathrm{OH}$ hampir sama seperti terlihat pada Gambar 3 (a dan b). Uranium dan thorium terpisah pada $\mathrm{pH} 4$, baik pada penambahan reagen $\mathrm{NaOH}$ maupun $\mathrm{NH}_{4} \mathrm{OH}$. Pada penelitian ini dipilih $\mathrm{NH}_{4} \mathrm{OH}$ sebagai reagen pengendapan karena penanganan hasil samping reaksi $\mathrm{NH}_{4} \mathrm{OH}$ dengan unsur dalam slag II lebih mudah dibandingkan dengan $\mathrm{NaOH}$. Hasil samping reaksi antara $\mathrm{NH}_{4} \mathrm{OH}$ dengan unsur dalam slag II berupa $\left(\mathrm{NH}_{4}\right)_{2} \mathrm{SO}_{4}$ yang dapat dihilangkan dengan proses pemanasan. $\left(\mathrm{NH}_{4}\right)_{2} \mathrm{SO}_{4}$ akan menguap menjadi gas $\mathrm{NH}_{4}$ dan $\mathrm{SO}_{2}$. Hasil samping reaksi $\mathrm{NaOH}$ dengan unsur dalam slag II berupa $\mathrm{Na}_{2} \mathrm{SO}_{4}$. $\mathrm{Na}_{2} \mathrm{SO}_{4}$ jika dipanaskan akan menghasilkan endapan $\mathrm{Na}$ yang akan menjadi pengotor dan perlu pengolahan lebih lanjut untuk menghilangkan $\mathrm{Na}$ dari endapan.

Selain kondisi $\mathrm{pH}$, kondisi optimum pengendapan juga dapat dipengaruhi oleh suhu dan waktu pengendapan. Suhu pengendapan yang semakin tinggi menyebabkan efektifitas reaksi uraniumthorium sulfat dengan $\mathrm{NH}_{4} \mathrm{OH}$ maupun $\mathrm{NaOH}$ akan semakin berkurang. Semakin tinggi suhu maka ion $\mathrm{OH}$ yang akan mengikat uranium dan thorium menjadi uranium dan thorium hidroksida akan berkurang. Suhu yang semakin tinggi menyebabkan ion $\mathrm{OH}$ berubah menjadi gas sehingga tidak ada cukup $\mathrm{OH}$ untuk mengikat uranium dan thorium menjadi uranium dan thorium hidroksida.

Waktu pengendapan berpengaruh pada lamanya reaksi antara uranium dan thorium sulfat dengan $\mathrm{NH}_{4} \mathrm{OH}$ atau $\mathrm{NaOH}$. Semakin lama waktu reaksi maka reaksi akan berjalan sempurna. Akan tetapi, suatu reaksi akan mencapai keadaan setimbang pada waktu optimum. Reaksi yang telah mencapai keadaan setimbang ditandai dengan tidak ada perubahan pada hasil reaksi apabila waktu reaksi ditambahkan.

Pengaruh suhu dan waktu pengendapan ditentukan berdasarkan kadar uranium dan thorium dalam filtrat. Tabel 2 dan Tabel 3 menunjukan kadar uranium dan thorium dalam larutan dengan variasi suhu dan waktu pengendapan.

Tabel 2. Data hasil analisis unsur dalam larutan dengan ICP-OES (variasi suhu).

\begin{tabular}{|c|c|c|c|c|}
\hline \multirow{3}{*}{$\begin{array}{c}\text { Suhu } \\
\left(^{\circ}\right)\end{array}$} & \multicolumn{4}{|c|}{ Kadar (ppm) } \\
\hline & \multicolumn{2}{|c|}{$\mathrm{NaOH}$} & \multicolumn{2}{|c|}{$\mathrm{NH}_{4} \mathrm{OH}$} \\
\hline & $\mathbf{U}$ & Th & $\mathbf{U}$ & Th \\
\hline 30 & ttd & $\mathrm{ttd}$ & $\mathrm{ttd}$ & $\mathrm{ttd}$ \\
\hline 40 & $\operatorname{ttd}$ & $\mathrm{ttd}$ & $\mathrm{ttd}$ & $\mathrm{ttd}$ \\
\hline 45 & $\mathrm{ttd}$ & $\mathrm{ttd}$ & $\mathrm{ttd}$ & $\mathrm{ttd}$ \\
\hline 50 & $\operatorname{ttd}$ & $\operatorname{ttd}$ & $\operatorname{ttd}$ & $\mathrm{ttd}$ \\
\hline 55 & $\operatorname{ttd}$ & $\operatorname{ttd}$ & $\mathrm{ttd}$ & $\mathrm{ttd}$ \\
\hline 60 & $\mathrm{ttd}$ & $\mathrm{ttd}$ & $\mathrm{ttd}$ & $\mathrm{ttd}$ \\
\hline 70 & $\mathrm{ttd}$ & $\mathrm{ttd}$ & $\mathrm{ttd}$ & $\mathrm{ttd}$ \\
\hline 80 & ttd & $\mathrm{ttd}$ & $\mathrm{ttd}$ & $\mathrm{ttd}$ \\
\hline
\end{tabular}


Tabel 3. Data hasil analisis unsur dalam larutan dengan ICP-OES (variasi waktu).

\begin{tabular}{|c|c|c|c|c|}
\hline \multirow{3}{*}{$\begin{array}{c}\text { Suhu } \\
\left({ }^{\circ}\right)\end{array}$} & \multicolumn{4}{|c|}{ Kadar (ppm) } \\
\hline & \multicolumn{2}{|c|}{$\mathrm{NaOH}$} & \multicolumn{2}{|c|}{$\mathrm{NH}_{4} \mathrm{OH}$} \\
\hline & $\mathbf{U}$ & Th & $\mathbf{U}$ & Th \\
\hline 10 & $\operatorname{ttd}$ & $\mathrm{ttd}$ & ttd & $\mathrm{ttd}$ \\
\hline 15 & $\operatorname{ttd}$ & $\mathrm{ttd}$ & $\mathrm{ttd}$ & $\mathrm{ttd}$ \\
\hline 30 & $\operatorname{ttd}$ & $\mathrm{ttd}$ & $\mathrm{ttd}$ & $\mathrm{ttd}$ \\
\hline 45 & $\mathrm{ttd}$ & $\mathrm{ttd}$ & $\mathrm{ttd}$ & $\mathrm{ttd}$ \\
\hline 60 & $\operatorname{ttd}$ & $\mathrm{ttd}$ & $\mathrm{ttd}$ & ttd \\
\hline 75 & $\operatorname{ttd}$ & $\mathrm{ttd}$ & $\mathrm{ttd}$ & $\mathrm{ttd}$ \\
\hline 90 & $\operatorname{ttd}$ & $\mathrm{ttd}$ & $\mathrm{ttd}$ & $\mathrm{ttd}$ \\
\hline 120 & $\mathrm{ttd}$ & $\mathrm{ttd}$ & $\mathrm{ttd}$ & $\mathrm{ttd}$ \\
\hline
\end{tabular}

Tabel 2 dan 3 menunjukan bahwa kadar uranium dan thorium dalam filtrat tidak terdeteksi untuk semua kondisi variasi suhu dan waktu pengendapan. Hal ini berarti kadar uranium dan thorium dalam filtrat sangat kecil atau kurang dari limit deteksi ICP-OES (<10 ppb). Kadar uranium dan thorium yang kecil menandakan bahwa uranium dan thorium telah mengendap sehingga kadar uranium dan thorium dalam filtrat sangat kecil. Pada penelitian ini, pengaruh suhu dan waktu pengendapan terhadap hasil proses pemisahan uranium dan thorium sulfat tidak dapat diketahui karena perubahan kadar uranium dan thorium dalam filtrat sangat kecil.

\section{KESIMPULAN}

Berdasarkan hasil penelitian dapat disimpulkan bahwa uranium dan thorium dapat dipisahkan dengan metode pengendapan. $\quad \mathrm{NH}_{4} \mathrm{OH}$ digunakan sebagai reagen pengendapan dengan kondisi optimum proses pada $\mathrm{pH}$ 4. Suhu dan waktu reaksi tidak mempengaruhi proses. Recovery pengendapan yang dihasilkan adalah $93,84 \%$ uranium dan $84,33 \%$ thorium.

\section{DAFTAR PUSTAKA}

1. SUPRAPTO, S.J., "Potensi, Prospek, dan Pengusahaan Timah Putih di Indonesia", makalah Ilmiah Kelompok Program Penelitian Konservasi-Pusat Sumber Daya Geologi, Jakarta, 2007.

2. FIRDAUS, O., "Tin Slag dan Timah Paduan", Bangka Pos, Bangka Belitung, 26 Oktober 2010.

3. PUSLITBANG TEKMIRA, "Hasil Analisis XRF”, Puslitbang Tekmira, ed 5 Juli, Bandung, 2010.

4. ANGGRAINI, M., WALUYO, S., dan RUSYDI, "Pemisahan Uranium dan Thorium dari Slag II Peleburan Timah dengan Metode Pelarutan", Prosiding Pertemuan dan Presentasi Ilmiah Fungsional Pengembangan Teknologi Nuklir VIII, Jakarta, 2014.

5. CUTHBERT, F.L., "Thorium Production Technology", Additon Wesley Publishing Company Inc, Massachusetts, USA, 1958.

6. KUNDARI, N.A., "Kinetika Kimia", STTN-BATAN, Yogyakarta, 2007.

7. AMER, T.E., ABDELLA, W.M., WAHAB, A.G.M., and EL-SHEIKH, E. M, "A Suggested Alternative Procedure for Processing of Monazite Mineral Concentrate", International Journal of Mineral Processing, 125, 106-111, 2013.

8. SUYANTI dan PURWANI, M.V., "Pengendapan Thorium dari Hasil Olah Pasir Monasit", Prosiding Pertemuan dan Presentasi Ilmiah Peneltian Dasar Ilmu Pengetahuan dan Teknologi Nuklir, 147154, 2011.

9. ARIEF, E.R., "Teori Praktikum Pelindian. Latihan Keahlian Teknologi Pengolahan Bijih Uranium", PPGN-BATAN, Jakarta, 1993. 
10. ANONIM, "Electrolyte, EMF, and

Chemical Equilibrium", Solubility

Product Constant, 2000. 